\title{
Regeneration of Plantlets via Direct Somatic Embryogenesis from Different Explants of Murraya koenigii. (L.) Spreng
}

\author{
Nisha Khatik ${ }^{1}$, Ramesh Joshi ${ }^{2}$ \\ Plant Biotechnology Laboratory, Department of Botany, S.P.C. Government College Ajmer, Rajasthan 305001, India
}

\begin{abstract}
An in vitro plant regeneration system was developed via direct somatic embryogenesis from different seedling explants of an important medicinal plant Murraya koenigii (L.) Spreng Cotyledons (COT), Hypocotyl (HYP) (10 to 15 mm) and Root (RT) segments (10 to $20 \mathrm{~mm}$ ) were excised from 60 days old seedling as explants. The somatic embryos induction was achieved on Murashige and Skoog (MS) basal medium augmented with different concentrations of 6-benzyleaminopurine (BAP) 1.33 to $8.40 \mu M$ and thidiazuron (TDZ) 1.08 to $9.82 \mu M$. The globular embryos originated from cut ends and entire surface of the root, hypocotyl explants and margins of cotyledons within 30-40 days. The percentage of somatic embryos induction per explant was significantly higher in HYP explants (94.21 $\pm 5.77 \%)$ in the MS basal medium supplemented with $6.20 \mu \mathrm{M} \mathrm{BAP}$ and $8.64 \mu \mathrm{M} \mathrm{TDZ}$. The highest rate of conversion of torpedo, heart and cotyledonary stages from globular stage was obtained in MS medium supplemented with $8.64 \mu M$ TDZ. The matured somatic embryos were transferred to the MS basal medium without Plant Growth Regulators (PGRs). Highest 88\% of the matured embryos were germinated on transfer to $1 / 2$ MS basal medium without PGR, where they grew for a further 3-4 weeks. Out of seventy six hardened plants seventy (92\%) plantlets were found healthy under field conditions.
\end{abstract}

Keywords: Murraya koenigii, Somatic embryogenesis, Thidiazuron, Rutaceae

\section{Introduction}

Murraya koenigii (L.) Spreng. locally known as "Curry patta" or " Meetha neem" belonging to the family Rutaceae that grows wildly in Southern Asia. Its aromatic leaves are commonly used as the raw material for traditional medicinal formulations in India. The leaves contain essential oil and also used as a condiment. Several monomeric and binary carbazol alkaloids present in the various plant parts [1]. These alkaloids have been reported to possess antimicrobial [2], [3], mosquitocidal, topo-isomerase inhibition [4]-[7] and antioxidant properties [8], [9]. Some of the alkaloids reported in this plant have showed anti carcinogenic [10], [11] and antidiabetic properties [12].

The conventional method of propagation of $M$. koenigii is by seeds only, which retain their viability for a short period. The biotechnological approach for genetic improvement and development of regeneration protocol is prerequisite for germplasm conservation through micropropagation and the development of transgenic plants. An efficient method of somatic embryogenesis is required for genetic improvement of this valuable medicinal plant. However, in vitro propagation of curry leaf plant through adventitious shoot proliferation from inter-nodal cuttings was reported by Joshi et al. [13]. Also in Citrus, close relative of M. koenigii, methods for genetic improvement by somatic hybridization have been reported by Grosser et al. [14]. Although few reports are available for in vitro studies of this plant which are restricted to the nodal and stem segments [15], [16] and from intact seedling [17]. Paul et al. [18] reported a regeneration system of direct and indirect somatic embryogenesis in this plant but they have used Zygotic embryonic axis and Cotyledon as explants only. The present communication reports an efficient translational protocol for regeneration of plants through direct somatic embryogenesis from Hypocotyl (HYP), Cotyledon (COT) and Root (RT) explants.

\section{Materials and Methods}

Plant material, explant preparation and cultures establishment

Ripe blackish purple colour fruits collected from matured tree of Murraya koenigii grown in campus and surrounding area of Ajmer were washed with running tap water for 15 minutes. Seeds were removed from fruits and washed free of pulp. Seeds were first washed with liquid detergent (Teepol; Qualigen, India) and then soaked with $0.1 \%$ solution of Bavistin fungicide (BASF, India) and rinsed with distilled water. The seeds were surface sterilized with an aqueous solution of $0.1 \%(w / v) \mathrm{HgCl}_{2}$ (Hi Media, India) for 5-6 minutes followed by four to five autoclaved distilled water rinses. Disinfected seeds were germinated in $200 \mathrm{ml}$ screwcapped glass jars containing $40 \mathrm{ml}$ seed germinating half strength micro and macronutrient Murashige and Skoog (MS) basal medium [19] devoid of plant growth regulators. Cotyledons (COT), Hypocotyl (10 to $15 \mathrm{~mm}$ ) and root segments (10 to $20 \mathrm{~mm}$ ) were excised from 60 days old seedling as explants.

\section{Culture media and experimental conditions}

For induction of direct somatic embryogenesis the explants were inoculated on MS medium supplemented with 1.33 to $6.20 \mu \mathrm{M}$ 6- benzylaminopurine (BAP) and 1.08 to $9.82 \mu \mathrm{M}$ thidiazuron (TDZ). Somatic embryos were further transferred to another set of MS medium supplemented with 1.08 to $9.82 \mu \mathrm{M} \mathrm{TDZ}$ for their maturation. Thus, for germination the matured somatic embryos were sub-cultured to $1 / 2$ basal MS medium free of plant growth regulators (PGR). All the cultures were maintained regular sub-culture after three to four weeks on the same medium. Media were solidified by adding $0.8 \%$ agar powder (Qualigen, India) and $3 \%$ sucrose were added as carbon source (Qualigen, India). The $\mathrm{pH}$ of media was adjusted to $5.8( \pm 0.1)$ before autoclaving. The media were autoclaved at $121^{\circ} \mathrm{C}$ Psi for 


\section{International Journal of Science and Research (IJSR) \\ ISSN (Online): 2319-7064}

Index Copernicus Value (2013): 6.14 | Impact Factor (2014): 5.611

twenty minutes. Cultures were maintained at $25 \pm 1^{\circ} \mathrm{C}, 16-\mathrm{h}$ photoperiod under $35 \mu \mathrm{E} \mathrm{m} \mathrm{m}^{-2} \mathrm{~s}^{-1}$ light intensity by white fluorescent tubes (Philips, India).

\section{Acclimatization and field transfer}

In vitro developed plantlets with 40-50 $\mathrm{mm}$ shoot length and strong root were washed with running tap water and were transferred into $200 \mathrm{ml}$ jars $1 / 3$ filled with a pasteurized mixture of vermiculite, perlite and peat moss in equal ratio. The plantlets in the screw capped jars were kept under a hardening unit for one week and then the screw caps were removed from bottle. They were later gradually transferred to the low humidity and high light intensity zone of hardening unit in the interval of one week. The plantlets were finally transferred to poly bags and exposed to field conditions.

\section{Statistical analysis}

All experimental data were subjected to analysis of variance (ANOVA) and significant $(P>0.05)$ means were determine with Duncan's Multiple- range test (DMRT) to distinguish differences between treatments means at the $\alpha=0.05$ level using SPSS or Windows version 16.0.

\section{Results}

\section{Induction of direct somatic embryos from COT, HYP and RT explants}

The somatic embryos induction was achieved on MS basal medium supplemented with different concentrations of BAP 1.33 to $8.40 \mu \mathrm{M}$ and TDZ 1.08 to $9.82 \mu \mathrm{M}$. The embryos originated from cut ends as well as from surface of the root, hypocotyl and margins of cotyledons within 30-40 days. However, the frequency of responding explants and number of somatic embryos per explants varied in different concentrations of PGRs and type of the explants. The percentage of somatic embryos induction per explant was significantly higher in HYP explants $(94.21 \pm 5.77 \%)$ whereas the lowest percentage of embryos $(79.25 \pm 1.66 \%)$ were formed from cotyledon explants in the MS basal medium supplemented with $6.20 \mu \mathrm{M}$ BAP and $8.64 \mu \mathrm{M}$ TDZ (Table 1). The somatic embryos formed in these media were of globular stages (Fig. 1a) only and they could not attain the advanced stages of somatic embryogenesis i.e. heart and torpedo stages even after culturing them for 60 days in the same medium.

Table 1: Effect of different concentrations of cytokinins upon the induction of somatic embryos from COT, HYP and RT explants of M. koenigii on MS basal medium containing 3\% sucrose and $0.8 \%$ agar.

\begin{tabular}{|c|c|c|c|c|c|}
\hline Sr. No. & \multicolumn{2}{|c|}{ Concentrations of PGRs $(\boldsymbol{\mu M})$} & \multicolumn{3}{|c|}{ Explants forming Somatic Embryos (\%) } \\
\hline & BAP & TDZ & HYP & RT & COT \\
\hline 1. & 0.00 & 0.00 & 0.00 & 0.00 & 0.00 \\
\hline 2. & 1.33 & & $14.22 \pm 2.11^{\mathrm{a}}$ & $18.12 \pm 3.71^{\mathrm{cd}}$ & $16.52 \pm 3.22^{\mathrm{jkf}}$ \\
\hline 3. & 1.33 & 1.08 & $28.32 \pm 1.74^{\mathrm{bc}}$ & $24.13 \pm 2.30^{\mathrm{efk}}$ & $22.71 \pm 1.25^{\mathrm{jf}}$ \\
\hline 4. & & 1.08 & $33.32 \pm 1.21^{\mathrm{de}}$ & $30.17 \pm 1.79^{\mathrm{jk}}$ & $28.55 \pm 3.35^{\mathrm{jj}}$ \\
\hline 5. & 1.55 & & $41.32 \pm 1.74 \mathrm{f}^{\mathrm{gh}}$ & $59.82 \pm 3.16^{\mathrm{df}}$ & $49.91 \pm 2.89^{\mathrm{cd}}$ \\
\hline 6. & 1.55 & 2.16 & $48.17 \pm 2.33^{\mathrm{jjk}}$ & $42.22 \pm 1.72^{\mathrm{ab}}$ & $49.25 \pm 1.66^{\mathrm{df}}$ \\
\hline 7. & & 2.16 & $55.21 \pm 5.77^{\mathrm{cde}}$ & $49.12 \pm 1.99^{\mathrm{cf}}$ & $48.11 \pm 2.88^{\mathrm{ab}}$ \\
\hline 8. & 3.11 & & $61.37 \pm 4.42^{\mathrm{ij}}$ & $58.29 \pm 2.98^{\mathrm{d}}$ & $55.72 \pm 2.62^{\mathrm{cb}}$ \\
\hline 9. & 3.11 & 4.32 & $72.82 \pm 2.99^{\mathrm{efg}}$ & $68.41 \pm 2.77^{\mathrm{cc}}$ & $67.33 \pm 3.33^{\mathrm{jk}}$ \\
\hline 10. & & 4.32 & $73.24 \pm 1.74^{\mathrm{b}}$ & $69.22 \pm 1.79^{\mathrm{ac}}$ & $68.11 \pm 2.88^{\mathrm{ab}}$ \\
\hline 11. & 6.20 & & $81.76 \pm 2.66^{\mathrm{c}}$ & $77.52 \pm 2.67^{\mathrm{bc}}$ & $72.76 \pm 2.51^{\mathrm{ac}}$ \\
\hline 12. & 6.20 & 8.64 & $94.21 \pm 5.77^{\mathrm{cdf}}$ & $84.41 \pm 2.77^{\mathrm{c}}$ & $79.25 \pm 1.66^{\mathrm{df}}$ \\
\hline 13. & & 8.64 & $82.27 \pm 3.27^{\mathrm{d}}$ & $70.59 \pm 3.35^{\mathrm{a}}$ & $66.77 \pm 2.76^{\mathrm{cg}}$ \\
\hline 14. & 8.40 & & $72.82 \pm 2.99^{\mathrm{efg}}$ & $68.41 \pm 2.77^{\mathrm{cc}}$ & $67.33 \pm 3.33^{\mathrm{jk}}$ \\
\hline 15. & 8.40 & 9.82 & $69.32 \pm 3.31^{\mathrm{ef}}$ & $59.82 \pm 3.16^{\mathrm{df}}$ & $71.72 \pm 2.62^{\mathrm{cc}}$ \\
\hline 16. & & 9.82 & $61.37 \pm 4.42^{\mathrm{ij}}$ & $78.66 \pm 2.92^{\mathrm{jh}}$ & $72.76 \pm 2.51^{\mathrm{ac}}$ \\
\hline
\end{tabular}

*PGRs plant growth regulators, BAP 6- benzylaminopurine, TDZ Thidiazuron

*Values are expressed as mean \pm standard error of mean (SE) taking five explants in each experiment with three replicates. Within each group, values with different letters are indicative of significant difference at $P>0.05$ using Duncan's multiplerange test (DMRT)

\begin{abstract}
Maturation and germination of somatic embryos
The globular stages of somatic embryos did not convert into next stages. The conversion percentage varied widely from 37 to $98 \%$ depending on the concentrations of growth regulators used. The highest rate of conversion of globular stage of embryos to torpedo, heart and cotyledonary stages was obtained from MS medium supplemented with $8.64 \mu \mathrm{M}$
\end{abstract}

TDZ (Fig. 2) which converted the highest $98 \%$ of globular embryo into further heart, torpedo (Fig 1. b) and cotyledonary stages (Fig. 1c) of somatic embryogenesis within three to four weeks The same basal medium when supplemented with higher concentrations of TDZ did not show any significant differences on the percentage of conversion.

\section{Volume 4 Issue 11, November 2015}




\section{International Journal of Science and Research (IJSR) \\ ISSN (Online): 2319-7064}

Index Copernicus Value (2013): 6.14 | Impact Factor (2014): 5.611

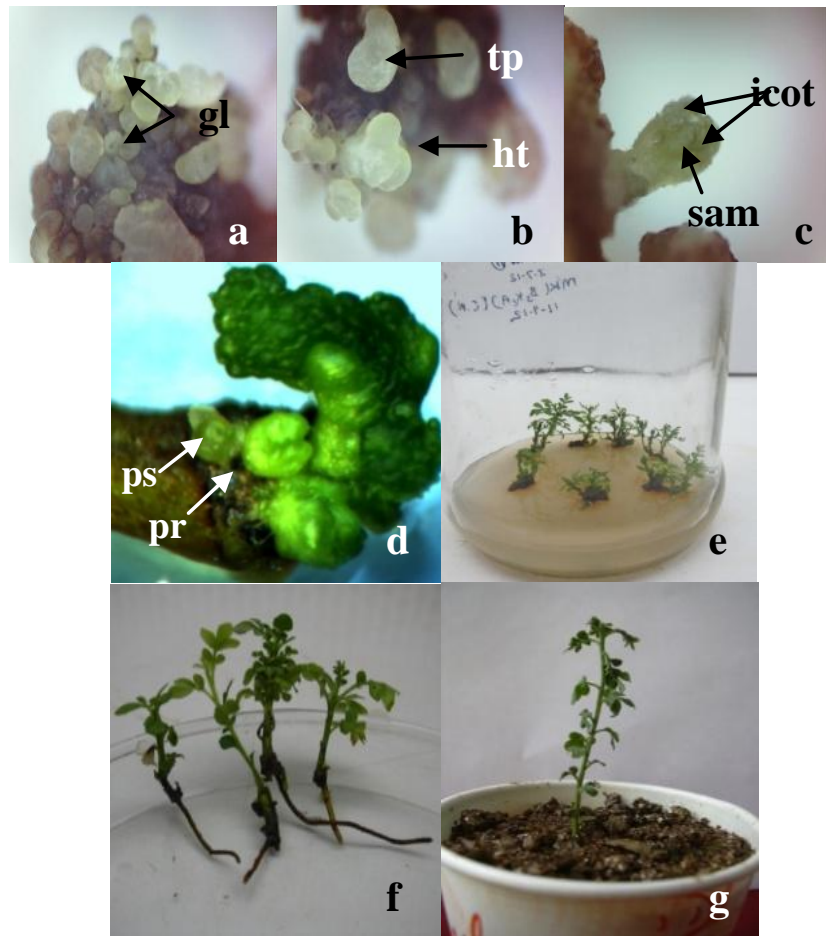

Figure: 1 [a-g] - Photomicrograph of different stages of direct somatic embryos in Murraya koenigii. (a): Globular (gl); (b): Torpedo(tp) and heart(ht) stages; (c): somatic embryo with shoot apical meristem (sam) and two initial cotyledons (icot); (d): germination of somatic embryo on mother tissues with primary shoot (ps) and primary root (pr) on $1 / 2$ MS medium without PGRs; (e): conversion of somatic embryos in to plantlets upon culture on $1 / 2$ MS basal medium without PGRs; (f): six week-old tap rooted plantlets prior to hardening; (g): hardened plantlet in nursery.

\section{Discussion}

In present study an improved regeneration system through direct somatic embryogenesis in M. koenigii was developed. The induction of direct somatic embryogenesis and their subsequent development are influenced by culture media, choice of explants and concentration and combinations of PGRs. Culture medium is one of the most important factors to be considered for in vitro plant cell culture. The MS medium is most common medium which has been reported to be used in plant regeneration via direct and indirect somatic embryogenesis [18] and by axillary and adventitious bud culture [13], [18], [15]. Alternatively B5 medium has been used for in vitro regeneration of Arabidopsis thaliana [20]. However, present study suggested that MS medium responded better than other culture media.

In general, relatively high auxin concentrations favor callus formation and induction of cell polarity. Afterwards, when somatic embryo induction stage has been achieved, it is necessary to reduce or eliminate the auxins because the embryos begin to synthesize their own auxin, possibly via an alternative pathway [21], [22]. In the species such as Zoysia japonica [23], Begonia gracilis [24] and Oncidium spp. [25], the use of cytokinins favors the induction of somatic embryos. In our study the BAP $6.20 \mu \mathrm{M}$ and TDZ $8.64 \mu \mathrm{M}$
The matured somatic embryos, either in clusters or individually, were transferred to the MS basal medium without PGRs, for their germination. Some of the $(10 \%)$ embryos germinated even when they were still attached to the mother tissues (Fig. 1d) and the highest $88 \%$ of the matured embryos were germinated on transfer to the PGR free medium where they grew for a further 4-6 weeks (Fig. 1e). Six weeks old plantlets with $5-6 \mathrm{~cm}$ shoots and well developed tap roots (Fig. 1f) were transferred to poly bags containing a mixture of perlite, vermiculite and peat moss in equal ratio. Out of seventy six hardened plants ninety two percent plantlets were found healthy under field conditions (Fig. 1g).

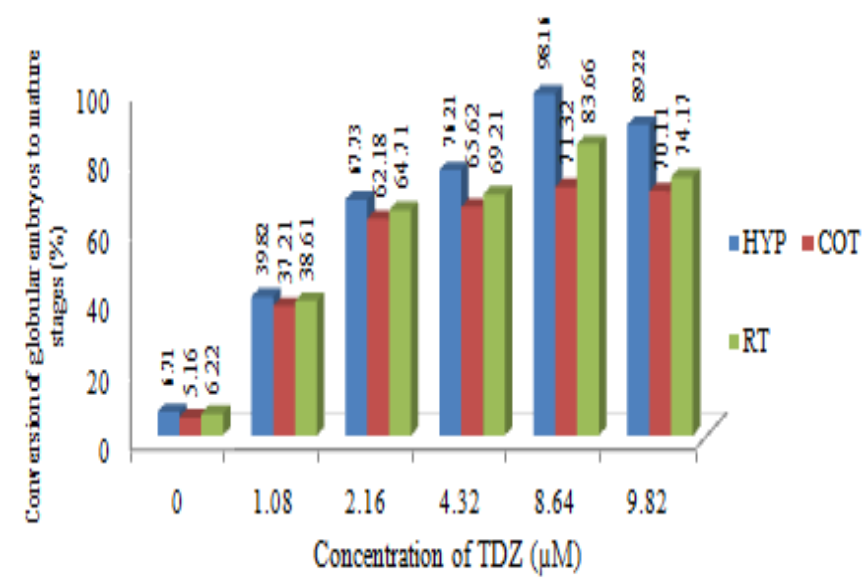

Figure: 2- Conversion of globular embryos to mature embryos (heart, torpedo and cotyledonary stages) in COT, HYP and RT explants of M. koenigii.

were found more effective for induction of globular embryos directly from HYP, COT and RT explants.

The TDZ a phenyl urea derivative (N-Phenyle-N1 - 1, 2, 3 thidiazol-5-ylurea) has a unique mode of action with intrinsic cytokinin like activity [26] and is known to be more effective than all adenine type cytokinins in inducing high frequency organogenesis in a number of plant species [27], [28] . Application of TDZ may increase the levels of endogenous cytokinins by inhibiting the action of cytokinin oxidase [29]. Present investigation revealed that the TDZ alone in the concentration of $8.64 \mu \mathrm{M}$ is prerequisite for conversion of $98 \%$ of globular embryos into torpedo and heart shape embryos. The germination or conversion of somatic embryo into plantlet is difficult during somatic embryogenesis [30]. For woody species in particular, the efficiency of germination is relatively low, which restricts application of somatic embryogenesis system for commercial purpose [31].

In our study it was observed that the matured somatic embryos could not germinate and even prolonged exposure to TDZ supplemented medium resulted in their distortion. Similar results have also been reported by Murch et al. [32] and Khurana et al. [33]. Inhibition of germination of somatic embryos by TDZ may be due to its high cytokinin activity

\section{Volume 4 Issue 11, November 2015}




\section{International Journal of Science and Research (IJSR) \\ ISSN (Online): 2319-7064}

Index Copernicus Value (2013): 6.14 | Impact Factor (2014): 5.611

[34]. In this study we have found that within 20 to 30 days the matured somatic embryos, recovered from HYP, COT and RT explants, were germinated on $1 / 2$ MS basal medium without PGRs.

The in vitro plantlets developed under low light, aseptic conditions and on the media containing sample of sugar and nutrients cannot survive in the external environmental conditions when directly placed in green house or field [35], [36]. The physiological and anatomical characteristics of micropropagated plantlets necessitate that they should be gradually acclimatized to the green house or field conditions [37]. The in vitro plantlets developed during the study program were successfully hardened and transfer to the field where $92 \%$ plants were found healthy.

In conclusion, we have developed an improved and viable regeneration system based on direct somatic embryogenesis from HYP, COT and RT explants of M. koenigii which can suffice the need of translational studies for lab to land technology. Furthermore, the investigation will potentially address the issues of large scale micropropagation and genetic transformation of $M$. koenigii and its close relatives.

\section{Acknowledgments}

Authors highly acknowledge University Grants Commission (UGC), New Delhi for the financial support and Dr. Vinod Joshi, Scientist 'Gee Desert Medicine Research Centre, Jodhpur for providing photo-micrographic facilities.

\section{References}

[1] M. Chakrabarty, A. C. Nath, S. Khasnobis, M. Chakrabarty, Y. Konda and Harigaya, Y. "Carbazole alkaloids from Murraya koenigii," Phytochemistry, 46, 1997, pp. 751-755.

[2] M. M. Rahman and A. I. Gray, "A benzoisofuranone derivative and carbazole alkaloids from Murraya koenigii and their antimicrobial activity", Phytochemistry, 66, 2005, pp. 1601-1606.

[3] Y. Tachibana, H. Kikuzaki, N. H. Lajis and N. Nakatani, "Antioxidative activity of carbazoles from Murraya koenigii leaves," J. Agric. Food Chemistry, 49, 2003, pp. 5589-5594.

[4] N. Salah, N. J. Miller, G. Paganga, L. Tijburg, G. P. Bolwell and C. Rice-Evans, "Polyphenolic flavanols as scavengers of aqueous phase radicals and as chain-

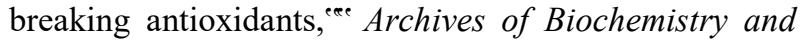
Biophysics, 322, 1995, pp. 339 - 346.

[5] J. T. Kumpulainen and J. T. Salonen, "Natural Antioxidants and Anticarcinogens in Nutrition," Health and Disease, The Royal Society of Chemistry, UK, 1999, pp. 178-187.

[6] S. K. Powers, K. C. Deruisseau, J. Quindry and K. L. Hamilton, "Dietary antioxidants and exercise," Journal of Sports Sciences, 22, 2004, pp. 81-94.

[7] L. Gomes, F. Leitao, A. V. Coelho and L. V. Boas, "Phenolic compounds and antioxidant activity of Olea europaea L, fruits and leaves," Food Sciences and Technology International, 12, 2006, pp.385-395.

[8] R. Joshi, B. L. Jat, A. Sharma, V. Joshi, N. Bohra and D. Nandwani, "In Vitro determination of antioxidant activity of Murraya koenigii L. Spreng," Functional Plant Science and Biotechnology, 5, 2011b, pp.75-77.

[9] M. B. Ningappa, R. Dinesha and L. Srinivas, "Antioxidant and free radical scavenging activities of polyphenol-enriched curry leaf (Murraya koenigii L.) extracts," Food Chem, 106, 2008, pp. 720- 728.

[10] M. K. Roy, V. N. Thalang, G. Trakoontivakorn and K. Nakahara, "Mechanism of mahanine-induced apoptosis in human leukemia cells (HL-60)," Biochem Pharmacolgy, 67, 2004, pp. 41-51.

[11]C. Ito, M. Itoigawa, K. Nakao, T. Murata, M. Tsuboi and N. Kaneda, "Induction of apoptosis by carbazole alkaloids isolated from Murraya koenigii," Phytomedicine, 13, 2006, pp. 359-365.

[12]A. N. Kesari, S. Kesari, S. K. Singh, R. K. Gupta and G. Watal, "Studies on the glycemic and lipidemic effect of Murraya koenigii in experimental animals," $J$. Ethnopharmacol, 112, 2007, pp. 305-311.

[13] R. Joshi, B. L. Jat, A. Sharma and D. Nandwani, "In Vitro propagation of Murraya koenigii (curry leaf plant) through adventitious shoot proliferation from internode explants," International Journal of Plant Developmental Biology, 5, 2011a. pp. 49-52.

[14] J. W. Grosser, P. Ollitrault and O. Olivares-Fuster, "Somatic hybridization in Citrus: an effective tool to facilitate variety improvement," In Vitro Cell Dev Biol Plant, 36, 2000, pp. 434- 449.

[15] G. R. Rout, "Direct plant regeneration of curry leaf tree (Murraya koenigii koenig.) an aromatic plant," In Vitro Cell. Dev. Biol-Plant, 41, 2005, pp. 133-136.

[16]K. Nirmal babu, A. Anu, A. B. Remashree and K, Praveen, "Micropropagation of curry leaf tree," Plant Cell Tiss. Organ Culture, 61, 2000, pp. 199-203.

[17]A. K. Bhuyan, S. Pattanaik and P. K. Chand, "Micropropagation of curry leaf tree (Murraya koenigii)," Plant Cell Rep, 16, 1997, pp. 779-782.

[18] S, Paul, A, Dam, A. Bhattacharyya and T. K. Bandyopadhyay, "An efficient regeneration system via direct and indirect somatic embryogenesis for the medicinal tree Murraya koenigii," Plant Cell Tiss. Organ Culture, 105, 2011, pp. 271-283.

[19] T. Murashige and F. Skoog, "A revised medium for rapid growth and bioassays with tobacco tissue cultures," Physiology Plant, 15, 1962, pp. 473-497.

[20] M. D. Gaj, Direct somatic embryogenesis as a rapid and efficient system for in vitro regeneration of Arabidopsis thaliana, Plant Cell Tissue and Organ Culture, 64, 2001, pp. 39-46.

[21] L. Michalczuk, T. J. Cooke and J. D. Cohen, "Auxin levels at different stages of carrot somatic embryogenesis," Phytochem, 31, 1992a, pp. 1097-1103.

[22]L. Michalczuk, D. M. Ribnicky, T. J. Cooke and J. D. Cohen, "Regulation of indole-3-acetic acid biosynthetic pathways in carrot cell cultures," Plant Physiol, 100, 1992b, pp. 1346-1353.

[23] Y. Asano, H. Katsumoto, C. Inokuma, S. Kaneko, Y. Ito and A. Fujiie, "Cytokinin and thiamine requirements and stimulative effects of riboflavin and $a$-ketoglutaric acid on embryogenic callus induction from the seeds of Zoysiajaponica Steud," Journal of Plant Physiology, 149, 1996, pp. 413-417. 
[24]B. Castillo and M. A. L. Smith, "Direct somatic embryogenesis from Begonia gracilis explants," Plant Cell Reports, 16, 1997, pp. 385-388.

[25] J. T. Chen and W. C. Chang, "Effects of auxins and cytokinins on direct somatic embryogenesis on leaf explants of Oncidium „Gower Ramsey"," Plant Growth Regulation, 34, 2001, pp. 229-232.

[26] M. C. Mok, D. W. S. Mok, D. J .Armstrong, K. Shudo, $\mathrm{Y}$ Isogai and T. Okamoto, "Cytokinin activity of Nphenyl-N"e, 3-thiadiazol 5-yl urea (thidiazuron), Phytochemistry, 21, 1982, pp. 1509-1511.

[27] B. N. S. Murthy, S. J. Murch and P. K. Saxena, "Thidiazuron: a potent regulator of in vitro plant morphogenesis," In Vitro Cell Dev Biol Plant, 34, 1998, pp. 268-276.

[28] M. K. Husain, M. Anis and A. Shahzad, "In vitro propagation of Indian kino (Pterocarpus marsupium Roxb.) using Thidiazuro," In Vitro Cell Dev Biol. Plant, 43, 2007, pp. 59-64.

[29]P. D. Hare and J. Van Staden, "Inhibitory effect of Thidiazuron on the activity of cytokinins oxidase from soybean callus," Plant Cell Physiol, 35, 1994, pp.11211125.

[30]B. S. C. Sutton and D. R. Polonenko, "Commercialization of plant somatic embryogenesis." In: S. M. Jain, P. K. Gupta, R. J. Newton (eds) Somatic embryogenesis in woody plants, vol 4 (Kluwer. Dordrecht, Germany) 1999, pp. 263-291.

[31] S. A. Merkle, K. A. Neu, P. J. Battle and R. L. Bailey, "Somatic embryogenesis and plantlet regeneration from immature and mature tissues of sweet-gum (Liquidambar styraciflua)," Plant Sci., 132, 1998, pp. 169-178.

[32] S. J. Murch, S. Krishna Raj and P. K. Saxena, "Tryptophan is a precursor for melatonin and serotonin biosynthesis in in vitro regenerate St. John's wort (Hypericum perforatum L. cv. Anthos) plants," Plant Cell Rep, 19, 2000, pp. 698-704.

[33]P. Khurana, S. Bhatnagar and S. Kumari, "Thidiazuron and woody plant tissue culture," J Plant Biology, 32, 2005, pp. 1-12.

[34]C. A. Huetteman and J.E. Preece, "Thidiazuron: a potent cytokinin for woody plant tissue culture," Plant Cell Tiss. Org. Cult, 33, 1993, pp. 105-119.

[35] B. N. Hazarika, "Acclimatization of tissue-cultured plants," Current Science, 85, 2003, pp. 1704-1712.

[36] B. N. Hazarika and A. Bora, "Hyperhydricity- A bottleneck to micropropagation of plants," Acta Horticulturae, 865, 2010, pp. 95-101.

[37]T. Kozai, "Micropropagation under photoautotrophic conditions", In: P. C. Debergh, R. H. Zimmerman (eds.) Micropropagation Technology and Application, (Kluwer Academic Publishers, Dordrecht - Boston London) 1991, pp. 447-469. 